\title{
LOS EMIGRANTES ESPAÑOLES EN PARÍS A FINALES DEL SIGLO XIX Y EN EL PRIMER TERCIO DEL SIGLO XX. LA SOCIEDAD DE SOCORROS MUTUOS EL HOGAR DE LOS ESPAÑOLES
}

\author{
por
}

\section{ANA FerNÁNDEZ ASPERILla}

Centro de Documentación de la Emigración Española. Fundación $1^{\circ}$ de Mayo.

RESUMEN: El artículo analiza la situación de los emigrantes españoles en París desde finales del siglo XIX y en el primer tercio del siglo XX. El estudio de la Sociedad Católica de Socorros Mutuos el Hogar de los Españoles permite reflexionar sobre el asociacionismo de los emigrantes en Francia y su transformación. Se investigan las razones de su creación, su funcionamiento y sus limitaciones. El ejemplo elegido representa solo un tipo de asociacionismo, pues desde el punto de vista de su origen, pueden señalarse otros dos: el impulsado por el estado y el surgido de la autoorganización de los emigrantes.

Palabras Clave: Relaciones España-Francia. Emigración. Asociacionismo. Iglesia católica.

ABSTRACT: This article analyses the situation of Spanish emigrants in Paris from the end of the nineteenth century and in the first third of the twentietb century. The study of the Sociedad Católica de Socorros Mutuos el Hogar de los Españoles allows reflection on the associations formed by emigrants in France and their transformation. The reasons for the creation of this particular Society, its functions, and its limitations are examined. The example chosen represents only one form of association, since in terms of origins there are two other forms: that promoted by the state, and that arising from the spontaneous self-organisation of emigrants.

KEY WORDS: Relations between France and Spain. Emigration. Associations. Catholic Church. 


\section{LOS ORÍGENES DEL ASOCIACIONISMO DE EMIGRANTES ESPAÑOLES EN FRANCIA}

Hasta mediados del siglo XX, América latina fue el principal destino de los emigrantes españoles. Por este motivo, la legislación reguladora se refería de modo casi exclusivo a los traslados ultramarinos ${ }^{1}$. A pesar de ello, en 1851 había 30.000 españoles en Francia y esta presencia se incrementó según avanzaba el siglo. Así sesenta años después el número se había triplicado. Los españoles se convirtieron en la tercera colonia extranjera más numerosa en el hexágono. Más de la cuarta parte de ellos trabajaban en la agricultura, acentuándose su peso en el sector con su presencia en las campañas de temporada. Los españoles vivían sobre todo en los departamentos del sureste y se fueron concentrando en los más vitícolas como eran Aude y Hérault.

Entre 1916 y 1919, la Gran Guerra incrementó las necesidades de trabajadores en Francia y el Servicio de la Mano de Obra Extranjera reclutó a 15.212 españoles para la industria bélica ${ }^{2}$. En 1921 el número de españoles era de 250.000 y diez años después se había incrementado en 101.864 personas. La clandestinidad y la falta de control en la contratación eran las principales características de esta emigración, que no estuvo regulada por un convenio como los sucritos por Francia con los gobiernos italiano y portugués ${ }^{3}$.

Esta importante presencia de emigrantes españoles en el país vecino desde finales del siglo XIX explica el origen y desarrollo del asociacionismo entre ellos. En este artículo desarrollaremos un estudio de caso mediante el análisis de la Sociedad de Socorros Mutuos El Hogar de los Españoles de la Pleine Saint Denis de París, fundada en 1926.

El interés de esta institución estriba, en efecto, en que permite indagar sobre los orígenes del movimiento asociativo español en Francia y su evolución. A partir de su creación, las organizaciones de emigrantes experimentaron una transformamación desde sociedades de socorros mutuos hasta asociaciones socioculturales. Es éste un fenómeno específico de Europa, y casi exclusivo de Francia, pues ha sido el único país del continente que cuando se produjo la emigración masiva a Europa, a mediados del siglo XX, contaba ya con una colonia importante asentada y un movimiento asociativo estructurado.

En América, por el contrario, ante la ausencia de un estado de bienestar, las asociaciones de españoles no han experimentado la evolución anterior. La ma-

1 TABANERA García, Nuria: «La política migratoria española entre la dictadura y la república (1923-1936): tutela y repatriación del emigrante español en América latina» en Exils et migrations ibériques au XX siècle (París) 7 (1999), pág. 77, YAÑEZ GALLARDO, César: la emigración española a América: siglos XIX y XX, Asturias, Fundación Archivo de Indianos, 1994 y VV.AA.: Historia general de la emigración española a Iberoamérica, Madrid, Ministerio de Trabajo y Seguridad Social, 1992.

2 Durante la Gran Guerra, el número de españoles en Francia alcanzaba el cuarto de millón.

3 Todos los datos en RuBIO, Javier: La emigración española a Francia, Barcelona, Ariel, 1974, págs. 89-167.

Hispania, LXII/2, núm. 211 (2002) 505-520 
yoría de ellas mantienen su carácter decimonónico original de sociedades de socorro mutuo. Dicho sistema obliga en la actualidad a la Administración española a invertir en planes de salud para hacer frente a los requerimientos sanitarios y a las dificultades médicas que atraviesan muchos españoles en los países americanos ${ }^{4}$.

Desde la segunda mitad del siglo XIX, el mutualismo conoció un espectacular desarrollo entre los emigrantes de América. Uruguay fue el pionero en la fundación de asociaciones españolas de socorros mutuos, pues en 1853 se creó la Asociación Española de Socorros Mutuos de Montevideo. Después se extendieron por Argentina, Brasil y Chile. En Argentina tuvieron un gran auge ya que entre 1857 y 1927 se habían creado 433 sociedades de socorros mutuos 5

A su vez, desde finales del siglo XIX y principios del XX, las sociedades españolas de socorros mutuos en Francia hicieron posible que los emigrantes recibieran cuidados médicos, ya que no fueron admitidos en los hospitales franceses hasta la firma del tratado hispano-francés de 2 de noviembre de 1932.

\section{LA INTERVENCIÓN DEL ESTADO ESPAÑOL EN RELACIÓN A LA EMIGRACIÓN en Parús: la Misión Española, el Real Patronato de SaNTa Teresa Y LA SOCIEDAD DE SOCORROS MUTUOS EL HOGAR DE LOS ESPAÑOLES}

La consideración de la emigración en España como parte de la cuestión social y su alcance cuantitativo en Francia explican la intervención de la monarquía y de la iglesia en relación con los españoles de París, como vamos a ver a continuación ${ }^{6}$.

Antes de centrarnos en la actuación concreta en la capital de Francia, conviene conocer la naturaleza del interés de la corona por la emigración. A este respecto resulta ilustrativo del paternalismo con que eran abordados sus problemas, la recomendación de los asesores de Alfonso XIII, con motivo de un

4 MuÑoz Oriol, María Angeles: "Atención y apoyo a los españoles residentes en el exterior», Revista del Ministerio de Trabajo y Asuntos Sociales (Madrid) 15 (1999), págs. 163-168.

5 NUÑEZ XeISAS, Xose Manoel: «Les paroisses d'autre mer» y LlORDEN MiÑAMBRES, Moisés: "Las asociaciones de inmigrantes españoles en América. Algunas respuestas a los desequilibrios y carencias de la emigración a ultramar», ambos en Exils et migrations ibèriques au XX siècle (París) 5 (1998), págs. 140 y 93-99 respectivamente; FERNANDEZ, Alejandro, «Los gallegos dentro de la colectividad y las asociaciones españolas en el primer tercio del siglo XX» y FERNÁNDEZ SANTIAGO, Marcelino X.: "Asociacionismo gallego en Buenos Aires (1936-1960)», en NUÑEZ SEIXAS, Xosé: La Galicia austral. La inmigración gallega en la Argentina, Buenos Aires, Editorial Biblo, 2001, págs. $139-161$ y $181-203$.

6 En 1881 se creó una comisión especial, encargada de elaborar las primeras estadísticas oficiales para conocer la magnitud del fenómeno migratorio. El motivo de su creación fue la muerte de emigrantes españoles por las tropas de Abu-Amena en Argelia, donde tanta importancia alcanzó la emigración española, aunque no la tratemos aquí, SANCHEZ ALONSO, Blanca: Las causas de la emigración española,1880-1930, Madrid, Alianza Editorial, 1995 , pág. 68. 
viaje del Rey a Londres y París en 1926, de dar un donativo a la Asociación de Beneficencia Iberoamericana, que trabajaba por los intereses de los españoles y americanos pobres en Inglaterra pues «sería de buen efecto entre estas gentes humildes y otros de su clase, el ver que nuestro amado soberano se ocupa siempre en todas partes de sus súbditos con paternal solicitud» ${ }^{7}$.

En 1926 existían en París diversos núcleos españoles significativos, ubicados en las zonas industriales del norte y nordeste de la capital. En Saint-Denis y Aubervilliers, los españoles representaban más del 37 por cien de los extranjeros, incluso llegaban a superar a los italianos. También había españoles en Saint-Ouen, en la Courneuve, en Drancy y en Blanc-Mesnil; en otros suburbios del oeste y del sur como Levallois-Perret, Colombes y Courbevoie y en torno a Vitry-Sur -Seine, Ivry- Sur-Seine y Choisy -le Roi.

Durante el período de entreguerras, los españoles eran mano de obra sin cualificar. Sólo el 6 por cien de los que vivían en 1936 en los suburbios de París eran empleados, incluidos los vendedores de ultramarinos o de vino. Los hombres trabajaban en la metalurgia, las construcciones mecánicas y las industrias químicas y las mujeres en el servicio doméstico. A principios de los años treinta del siglo XX tenían, junto con los africanos y los asiáticos, las tasas más altas de analfabetismo ${ }^{8}$. En su mayoría procedían de Levante (Castellón, Valencia, Alicante y Murcia). En Aubervilliers eran campesinos muy pobres de Cáceres y Castilla que habitaban casas miserables, construidas por ellos mismos con materiales de desecho.

La Pleine Saint Denis, ubicado entre los territorios de Saint Denis y Aubervilliers, era un barrio donde a finales del siglo XIX había una colonia española de poca importancia, que fue incrementándose. En 1911 la comunidad española representaba cerca del 18 por cien de los extranjeros. Diez años después, con 1.353 personas, alcanzaban el 34,1 por cien. A principios de siglo, los españoles trabajan sobre todo en la Cristalera Legras, en la fábrica de alambres Mouton y en la fábrica de productos químicos de Landy, donde desempeñaban actividades descualificadas y penosas 9 . Los españoles del barrio soportaban unas condiciones de explotación que fueron denunciadas por la prensa socialista francesa en 1912. A pesar de la prohibición del trabajo de menores de 13 años, muchachos de entre 10 y 16 años eran reclutados en el norte de Burgos y en el

7 Cfr. cartas de 9 de junio y 27 de junio de 1926 entre el Duque de Miranda y el Marqués de Torres de Mendoza, en Archivo General de Palacio. Caja 155522, exp. 4 y caja 888 expediente 34.

8 Según una descripción de los españoles de Aubervilliers del periódico La Voz de Madrid de 1938, citado por DREYFUS-ARMAND, Genèvieve: «L'inmigration espagnole en banlieue parisienne: la diversité», en BRUNET, Jean Paul: Inmigration vie polítique et populisme en balieue parisienne à fin XIX-XX siècle, París, L' Harmattan, 1995, págs. 131-153. La percepción francesa de los emigrantes españoles coincidía con la anterior pues los consideraban especialmente míseros, incultos y dispuestos a aceptar los trabajos más duros a cualquier precio, según RUBIO, J.: La emigración española a Francia, op. cit., pág. 110.

9 DREYFUS ARMAND, Geneviève: «L' inmigration...», op. cit., págs. 131-135. 
sur de Santander para trabajar en París jornadas de 14 horas, en contacto con el fuego, en las fábricas metalúrgicas y de vidrio de la zona ${ }^{10}$.

A partir de 1920, la Pleine Saint Denis se convirtió en un barrio español. El 80 por cien de la población que habitaba las barracas de las angostas y desiguales callejuelas eran de este origen y pronto empezó a ser conocido por sus vecinos franceses como La pequeña España. En 1931, 5.300 españoles vivían allí y más de 10.000 en la periferia norte de París, incluyendo los municipios de la Courneuve, Drancy, Saint-Ouens, Pantin y Blanc-Mesnil.

El primer tercio del siglo XX fue un período de tensión social en España ${ }^{11}$. Para neutralizar el empuje creciente de las organizaciones obreras, la iglesia desplegó una importante actividad en el campo de la acción social, en la que encaja la iniciativa de Alfonso XIII de enviar a París en 1913, bajo las órdenes de la embajada, a su capellán Gabriel Palmer, para fundar «una obra religiosa y patriótica» que mejorara las difíciles condiciones de los emigrantes españoles 12. Se dedicaría a

«estudiar las obras de carácter social o religioso (...) existentes, en beneficio de españoles necesitados, y las reformas que en las mismas deberían introducirse, para su mayor eficacia bajo el punto de vista del mejoramiento de la condición de nuestros compatriotas»13.

10 LILlo, Natacha: «Un barrio obrero junto a París que se convirtió en el hogar de muchos emigrantes», España Exterior, 19 de marzo 2002, pág. 10.

11 Casi el 20 por cien de la población asalariada de la industria y el transporte estaba afiliada a sindicatos, con una tendencia a su fortalecimiento y a la superación del societarismo. Además de la Semana Trágica de Barcelona en 1909, en 1911 se produjeron campañas contra la intervención en Marruecos, por la revisión del proceso de Ferrer, huelgas generales en Cádiz y Vizcaya y la convocatoria de huelga nacional por la UGT y la CNT. La suspensión de las garantías constitucionales, la clausura de los locales obreros, la intervención judicial de la UGT y la declaración de ilegalidad de la CNT fueron las respuestas gubernamentales ante el incremento de la tensión social. A pesar de la fuerte represión, la UGT siguió creciendo. El socialismo alcanzaba también representación parlamentaria y municipal y se creaba en Madrid la Casa del Pueblo. Como en el resto de países europeos nacía en los años veinte, resultado de un excisión del Partido Socialista el Partido Comunista, a consecuencia del éxito de la revolución bolchevique en Rusia, (véase TUÑón DE LARA, Manuel, $E l$ movimiento obrero en la bistoria de España, Madrid 1986, Vol. II, págs 25-59).

12 En 1905, con motivo del viaje del monarca a París, Dominga Arbe, natural de Vizcaya, que se trasladó a París con 30 años para ganarse la vida, solicitaba al rey un socorro, por carecer de dinero y de salud; Fidel Alarge, tornero del hierro en paro en París tuvo que ser repatriado y el consulado le facilitó un billete, el testimonio de ambos, que sirve para ilustrar las condiciones de los emigrantes, puede consultarse en Archivo General de Palacio, Caja 155515, exp. 4. Véase también sobre el envio del capellán a París, "Letras testimoniales de don Gabriel Palmer y Verger», en Archivo General de Palacio. Personal, Caja 1225, Exp. 25 y «Carta manuscrita de Gabriel Palmer a D. Manuel Hernández de 17 de marzo de 1930» Fondo del Hogar de los españoles, exp. 1/9 en Fundación $1^{\circ}$ de Mayo. Centro de Documentación de la Emigración Española ( a partir de ahora CDEE).

13 Cfr., «Escrito del jefe superior de palacio de 5 de febrero» en Archivo General de Palacio. Personal, Caja 1225, Exp. 25. 
En París, Palmer desplegó una actividad intensa, entre la que destaca la instalación de la Misión Española en la Iglesia de la calle de la Pompe 51bis, en el distrito XVI, uno de los más elegantes de París, donde las españolas trabajaban como domésticas ${ }^{14}$.

Allí pronunció sermones y tramitó expedientes matrimoniales entre los obreros españoles de la Pleine Saint Denis, Aubervilliers, Prés de S. Gervais, Pantin, Bagnolet, Gentilly, Neuilly y Levallois Perret. Creó varios centros catequísticos y una asociación de caridad de Santa Rita. Visitó a enfermos en hospitales y creó un centro obrero y un dispensario de asistencia médica gratuita. Finalmente consiguió que el Cardenal Arzobispo de París declarase que el Ministerio Religioso de la Misión se extendiese a toda la colonia de lengua española de París ${ }^{15}$.

Con el respaldo de la Monarquía se fundaba en 1922 otra misión católica en la Pleine Saint Denis, denominada «Real Patronato Español de Santa Teresa», elegida como centro de evangelización de la zona norte de París, donde se encontraba la colonia española más numerosa ${ }^{16}$.

En 1926 se creaba, también en la Pleine Saint Denis, la Sociedad de Socorros Mutuos el Hogar de los Españoles. Su objetivo era

«desenvolver el sentido de economía y de previsión para las múltiples necesidades del día de mañana; socorro mutuo entre sus socios en todas las vicisitudes de la vida, conforme a las circunstancias y al estado de fondos» ${ }^{17}$.

La Sociedad de Socorros Mutuos el Hogar de los Españoles era teóricamente un instrumento apolítico, destinado a remediar la precaria situación de los trabajadores españoles en la capital francesa, que no se oćpaba de asuntos "políticos, ni contrarios al dogma, ni a la moral»" ${ }^{18}$. Con una fuerte influencia eclesiástica, constituyó en realidad un mecanismo de control sobre las actividades de los emigrantes económicos en París, rasgo que caracterizará también a muchas organizaciones que a mediados del siglo XX impulsaron el Estado español y la Iglesia en el extranjero ${ }^{19}$. Junto a la recristianizaciación de los emigrantes, evitar su politización constituía el objetivo perseguido ${ }^{20}$.

14 Véase TABOADA LEONETTI, Isabelle: Les immigrés des beaux quartiers. La communauté espagnole dans le XVIe, París, L'Harmattan, 1987.

1s Su labor le hizo merecedor, en mayo de 1913, de la Cruz de Caballero de la Legión de Honor, concedida por el gobierno francés. Asimismo, Alfonso XIII le nombraba en 1916 visitador de la Misión, véase en «Letras testimoniales...», loc. cit.

16 Comisión EPISCOPAl De Emigración, Memoria de la Comisión Episcopal de emigración desde su constitución hasta la fecha, Madrid 1962, en Fundación $1^{\circ}$ de Mayo. CDEE.

17 Cfr. «Reglamento de El Hogar de los Españoles», Fondo del Hogar de los Españoles, loc. cit., exp. $1 / 1$

18 Cfr., «Reglamento...», loc. cit., exp. 1/1, art. 25.

19 Se contemplaba la posibilidad de extender la influencia de la obra y fundar sucursales de la sociedad de la Pleine Saint Denis. En enero de 1930 en L' Havre una sociedad de sociedad de socorros mutuos manifestaba sus deseos de ponerse bajo la tutela del Hogar, véase Fondo del Hogar de los 
Con el apoyo de la Monarquía, la intervención de la Iglesia en el socorro pretendía evitar el surgimiento de sociedades obreras de resistencia ${ }^{21}$. El catolicismo social intentaba frenar así el avance entre los trabajadores de las doctrinas que proclamaban la lucha de clases, proponiendo la armonía entre capital y trabajo. Sobre todo, porque desde finales del siglo XIX París era un foco de agitación revolucionaria contra la monarquía española, animado por exiliados republicanos y anarquistas que influían sobre los emigrantes a través de periódicos y de centros como la Federación Anarquista de Lengua Española de la Seine. Sin que hubieran desaparecido los vestigios de los exiliados carlistas y zorrillistas, tomaban el relevo de la subversión grupos anarquistas y republicanos representados por Ferrer, Vallina, Tárrida del Mármol o Lerroux.

Las estrategias revolucionarias contaban con apoyo internacional. En 1905, cuando Alfonso XIII salió ileso de un atentado terrorista perpetrado en París por un anarquista, su visita estuvo precedida por una campaña de boicoteo, organizada por socialistas e internacionalistas franceses. La Federación de la Seine conminaba a acatar la consigna de boicoteo al presidente del Consejo Municipal, el Sr. Brouse, de filiación socialista, dispuesto a desobedecerla y a cumplir con el protocolo que su condición municipal le exigía ante la llegada del Rey de España ${ }^{22}$.

En 1926, año de la fundación del Hogar de los Españoles, el propio monarca en un viaje a la capital francesa sería el objetivo de otro atentado preparado por los anarquistas Durruti y Ascaso ${ }^{23}$.

Españoles, loc. cit. , exp. 1/5. Probablemente el esquema que se preveía era el de la fusión o unión de sociedades de base en una organización centralizada para abaratar las cargas económicas, según RALLE, Michel: «La función de la protección mutualista en la construcción de una identidad obrera (1870-1910)», en CASTILLO, Santiago (ed.): Solidaridad desde abajo, Madrid, 1994, pág. 423 y el propio CASTILlO, Santiago, «Las sociedades de Socorros Mutuos en la España Contemporánea», en la misma obra, págs. 1-31.

20 ESTEBAN DE VEGA, Mariano: «La asistencia liberal española: beneficencia pública y previsión particular» en Historia Social (Valencia) 13 (1992), pág.132.

21 Sobre el peligro de la conversión de las sociedades obreras de socorros mutuos en reivindicativas y subversivas, CASTEL, Robert, Les métamorphoses de la question sociale, París, Fayarda, 1995, pág. 252. También, Alvarez URua, Fernando, «Los visitadores del pobre. Caridad, economía social y asistencia en la España del siglo XIX» en VV.AA.: De la beneficencia al bienestar social: cuatro siglos de acción social, Madrid, Consejo General de Colegios Oficiales de Diplomados en Trabajo y Asistentes Sociales, 1988, pág. 143.

22 En «Bulletin Politique», en Semaine Coloniale, 30 de mayo de 1905. Coincidiendo con el mismo viaje del monarca a París otras publicaciones francesas se hacían eco de la actividad de los anarquistas españoles en el país vecino y de las detenciones que llevó a cabo la policía francesa para garantizar la seguridad del joven monarca. En Narbonne y en Perpignan diversos anarquistas españoles fueron detenidos e interrogados, incautándoseles documentación y numerosos periódicos anarquistas procedentes de España, en «La surveillance des anarchistes» en Journal du Soir, 29 de mayo de 1905 y «Le voyage du Roi d' Espagne» en Liberte, 30 de mayo 1905, consultados en Archivo General de Palacio. Caja 15515, exp. 2.

23 No nos detenemos en explicar la actividad que estos grupos de exiliados y opositores a la Dictadura de Primo de Rivera desplegaron porque puede verse en BACHOUD, Andrée, «Notes sur

Hispania, LXII/2, núm. 211 (2002) 505-520 
En los años veinte y treinta del siglo XX la CNT y la FAI ejercían gran influencia entre la colonia española de La Pleine Saint Denis. Allí distribuían sus períodicos, organizaban mítines y representaciones teatrales. El Partido Comunista Francés y el sindicato mayoritario de los metalúrgicos incitaba a algunos españoles, escasamente politizados cuando emigraron, a incoporarse a sus filas ${ }^{24}$. El apoyo de la Monarquía a la intervención eclesial en París trataba de neutralizar la influencia de los exiliados sobre los obreros emigrantes y perseguía el mantenimiento del orden público, pues la mayoría de los residentes en la capital francesa deseaban retornar a España, trayendo con ellos sus militancias y filiaciones políticas.

Las vinculaciones entre emigración y anarquismo no eran privativas de Francia. En Argentina el nacimiento del movimiento obrero estuvo estrechamente ligado a la presencia de inmigrantes de origen español e italiano. Hasta tal punto que se promulgaron la «Ley de Residencia» en 1902, para expulsar a los extranjeros indeseables, anarquistas sobre todo, y una Ley de Defensa Social en 1910, que simbolizaba el miedo al inmigrante ${ }^{25}$. En el Río de la Plata, las autoridades españolas ejercían una estrecha vigilancia sobre las conexiones de los inmigrantes con la Península Ibérica. El temor estaba motivado no por la situación argentina sino por la española, donde la agitación social llevó a tomar precauciones al otro lado del Atlántico, y como no podía ser de otro modo, y por razones de vecindad, también al otro lado de los Pirineos. Pues Francia representaba, en definitiva, un escenario para la disidencia desde el que los grupos marginados del sistema político actuaban, intentando implicar en sus estrategias opositoras a los emigrantes económicos.

Georges Mauco, responsable francés de política migratoria, denunciaba en 1932 la amalgama de intereses entre los países exportadores de mano de obra y los patronos franceses. Los primeros seguían influyendo en sus emigrados, a través de misiones religiosas o colegios privados. Así les sustraían del contacto con los asalariados autóctonos y les alejaban de las reivindicaciones sociales, lo que interesaba a los patronos franceses ${ }^{26}$.

l'émigration espagnole avant la guerre civile» en Emigrations et exil au XX siècle (París) 2 (1996) págs. 11-23, y sobre todo en GONZÁLEZ CALLEJA, Eduardo: «La frontera como protagonista histórico. Observaciones sobre la emigración y la resistencia políticas en la primera etapa de la Restauración (18751900)", en Exils et migrations ibériques au xx siècle (París) 3-4 (1997) págs. 14-37, ALvAREZ JUNCO, José: «Un anarquista español a comienzos del siglo XX: Pedro Vallina en París» en Historia Social (Valencia), 13 (1992) págs. 23-37, SÁNCHEZ ALONSO, Blanca, las causas de la emigración..., op. cit. también señala la creencia del peligro de que el socialismo y el anarquismo se extendieran entre los emigrantes, sobre todo en los escritos del sacerdote José Polo Benito, págs. 79 y 81 .

24 Lillo, Natacha: «La crisis económica, la guerra civil y la invasión nazi marcaron a la colectividad española», España Exterior, 26 de marzo de 2002, pág. 10.

25 VIEITES TORREIRO, Dolores: «La participación de los gallegos en el movimiento obrero argentino (1808-1930)» en NUÑEZ XEISAS, Xosé: La Galicia austral..., op. cit., pág. 161-180.

26 SCHOR, Rapahel: Histoire de l'immigrarion en France, París, Armand Colin, 1996. 
La instalación en París de las misiones religiosas y la política migratoria de Primo de Rivera ratifican la hipótesis del responsable francés. La Ley de Emigración de 1924 ampliaba la protección del emigrante al extranjero y preveía la subvención de asociaciones que mantuvieran vivo el espíritu patriótico de socorros mutuos, de modo que se convertírían en mecanismos de influencia estatal sobre la actividad de los emigrados ${ }^{27}$.

El Hogar de los Españoles se adecuaba a los objetivos anteriores. Era una sociedad de socorros mutuos que ofrecía un seguro de enfermedad, asistencia médica y medicinas. No cubría otras contingencias como el desempleo, la vejez o la maternidad ${ }^{28}$, pero la cobertura fue ampliándose en cuanto a los beneficiarios y a las prestaciones ${ }^{29}$.

La asociación marginaba en función del género a las mujeres y a los trabajadores que no suscribieran la moral católica. Como ocurrió con un socio, que convivía con su mujer sin estar casado ${ }^{30}$. El control político y el encuadramiento dentro de la moral católica primaban como objetivos sobre el socorro a los trabajadores en situaciones de precariedad.

Para ser socio numerario del Hogar de los Españoles había que ser asalariado, presentar un certificado médico de buena salud y ser hombre de entre 16 y 55 años de edad. En los cinco primeros meses se permitió también la entrada de hombres de 60 años o de viudas, si el marido estaba al tanto de pago, con los mismos deberes y derechos, pero sin voz ni voto.

Entre las obligaciones de los socios se encontraba la de aportar 10 francos al mes por adelantado, pagar las multas impuestas por el retraso en los pagos, asistir, obligatoriamente, a las asambleas generales o justificar previamente su ausencia y contribuir con la entrega a la familia de los socios fallecidos de 2 francos para sufragar los gastos del funeral y el entierro. Entre los derechos estaba recibir las visitas regulares de los visitadores y del doctor, percibir los medicamentos y un socorro en metálico de 5 francos diarios durante los 90

27 TABANERA GarCía, Nuria: «La política migratoria española entre la dictadura y la república (1923-1936)...", op. cit., págs. 80-82.

28 La cobertura era muy limitada porque no cubría los partos ni la atención a las esposas e hijos de los socios, aunque en 1928 el médico de la sociedad se ofrecía para recomendar a las mujeres una partera que les haría una buena rebaja. La cobertura de las esposas u otros miembros de la familia era objeto de constantes discusiones por la Junta Directiva, hasta que en enero de 1928 se permitió que aquellas se beneficiaran también de los servicios de la sociedad. En 1929, se planteará la necesidad de extender los servicios a toda la familia. A partir de 1932, tras las gestiones de la Embajada, la asociación tuvo derecho a dos camas hospitalarias. En 1941 se pagó el socorro por nacimiento de hijos y en 1943 por accidente, en Fondo del Hogar de los Españoles, loc. cit., exp. 3/1 y 3/3.

29 Como ocurrió con otras sociedades de socorros mutuos, véase MONTERO, Feliciano y ESTEBAN DE VEGA, Mariano: «Aproximación tipológica al mutualismo popular y obrero en España: el mutualismo asistencial ", en CASTILLO, Santiago (Coord.): La Historia Social en España. Actualidad y perspectivas, Madrid, 1990, págs. 463-464.

30 "Acta de la Asamblea General Ordinaria del día 11 de marzo de 1928", Fondo del Hogar de los Españoles, loc. cit. , exp. 3/3.

Hispania, LXII/2, núm. 211 (2002) 505-520 
primeros días de la enfermedad, de 7 en caso de hospitalización y de 12 cuando el socio vivía lejos. Si la enfermedad se prolongaba, la Junta Directiva adoptaba medidas especiales. Si fallecía, la viuda recibía 200 francos; de ellos, 50 se destinaban a la compra de una corona ${ }^{31}$.

Existían también otras tres categorías de socios encargados del control y encuadramiento de los socios numerarios: bienhechores, honorarios y adherentes. La gestión de la asociación estaba en manos de eclesiásticos y de socios protectores. Es decir notables externos, personas de alta posición social que contribuían a la financiación y que ejercían, sobre todo, una función de control, moralización y vigilancia sobre los obreros asociados ${ }^{32}$. Los socios protectores dotaban a la organización de un carácter paternalista, en el que prevalecía la idea de beneficencia y de control político. En coincidencia con la visión de la monarquía, señalada más arriba.

La organización reproducía el modelo de sociedad mutualista de los Círculos Católicos de Obreros ${ }^{33}$, en los que el consiliario desempeñaba funciones que le conferían una gran influencia y poder. Era él el encargado de reclutar socios protectores, así como de la gestión económica de los fondos y de la representación de la sociedad ${ }^{34}$. Las decisiones del consiliario eran decisivas también para el desenvolvimiento cotidiano de la asociación.

En 1929, a partir de la Ley de Seguros Sociales francesa, la asociación se interesó por la cobertura que podrían recibir los obreros españoles y se decidió inscribirla en una federación, preferentemente de carácter católico ${ }^{35}$. La Federación Departamental del Sena Unión y Trabajo y la Familiale fueron las seleccio-

31 «Reglamento...», loc. cit., exp. 1/1, arts. 30, 31, 32,37, 46 y 50.

32 El reclutamiento de socios protectores era una labor en la que participaban los sacerdotes Ignacio Turrillas y Severiano Betelu. Entre los socios protectores, además de los propios padres se encontraba el propio Patronato de Santa Teresa, «Acta de la Junta directiva celebrada el 18 de diciembre de 1927» y «Junta de la Directiva del día 12 de abril de 1942», Fondo del Hogar de los Españoles, loc. cit., exp. 3/1.

33 Los círculos católicos obreros cumplen, junto con el religioso-moral, un objetivo de «defensa social» al servicio de los intereses contrarrevolucionarios, véase ESTEBAN DE VEGA, Mariano: «La asistencia liberal española: beneficencia pública y previsión particular», op. cit., pág. 134; CASTILLO, Santiago: "Las sociedades de socorros mutuos en la España contemporánea», op. cit., RODRíGUEZ OCAÑA, Esteban: «Medicina y acción social en la España del primer tercio del siglo XX» y sobre todo MONTERO, Feliciano, «Catolicismo y reforma social en España en el tránsito del siglo XIX al XX», ambos en VV.VV.: De la beneficencia..., op. cit.., págs. 249-257 y 171-176.

34 Se encargó por ejemplo de trasmitir al embajador la petición de una aportación económica al rey Alfonso XIII, según «Acta de la sesión de la Junta Directiva celebrada el día 9 de diciembre del año 1928», Fondo El Hogar de los Españoles, loc. cit., exp. 3/1.

35 "Acta de la sesión de la Junta Directiva del mes de mayo de 1929", Fondo del Hogar de los españoles, loc. cit., exp. $3 / 1$ y $1 / 13$.

Hispania, LXII/2, núm. 211 (2002) 505-520 
nadas, optando finalmente por la segunda ${ }^{36}$. La asociación organizó una conferencia en castellano para informar sobre el tema a todos los españoles ${ }^{37}$.

En la década de los años treinta se registraron, dentro de la Junta Directi$\mathrm{va}$, algunas tensiones y manifestaciones de carácter anticlerical ${ }^{38}$. La crisis económica hizo crecer el desempleo de los españoles en Francia. Muchos de ellos se encontraban en la indigencia. En 1932 y 1933, cuando los trabajadores españoles de la Courneuve tenían dificultades para cobrar el desempleo, Gabriel Palmer ofrecía como solución abrir una suscripción encabezada por él mismo, con diez francos diarios, además de otros donativos ${ }^{39}$.

En pleno período republicano, los trabajadores españoles del Hogar, junto con otras corporaciones obreras como El Deportivo Español de París, El Trovador y la Sección de Exploradores Españoles de París, buscaban, directamente en su embajador, una solución a sus problemas. Por ello le exponían por escrito la manera irrespetuosa en que habían sido recibidos en el Ayuntamiento de Aubervilliers, cuando pretendían acogerse al socorro por desempleo ${ }^{40}$. En 1935 el presidente planteaba de nuevo al embajador las dificultades encontradas por los hijos de los jornaleros para obtener el permiso de trabajo, ante la negativa del gobierno francés de 1934 de conceder nuevos permisos. En 1936 la mitad de los españoles de la colonia estaba en paro, lo que junto con las expectativas de reforma agraria que despertó el triunfo del Frente Popular en España, hizo que muchos retornaran. Otros en cambio, con la intención de garantizar un futuro mejor a sus hijos, se quedaron y se nacionalizaron.

Las soluciones ofrecidas por el Estado español en el primer tercio del siglo $\mathrm{XX}$ a los problemas de los emigrantes en París consistían en la caridad privada, tutelada por la Iglesia católica, cuando este esquema experimentaba una fuerte crisis y se había iniciado en España, desde mediados del siglo XIX, un proceso de «secularización» de la asistencia ${ }^{41}$. Se trasladaba al país vecino y para los obreros españoles allí residentes, el modelo de mutualismo católico vigente en España a partir de la década de los noventa del siglo XIX, inserto en un pro-

36 «Acta de la Asamblea General Ordinaria del día 29 de marzo de 1931», Fondo del Hogar de los Españoles, loc. cit., exp. 3/3. La ley de seguros sociales francesa obligaba a introducir ciertos cambios en el reglamento y funcionamiento de la sociedad, así como a federarse, según "Acta de la asamblea general extraordinaria del 30 de junio de 1929", Fondo del Hogar de los Españoles, loc. cit., exp. 3/3.

37 Celebrada el 23 de junio de 1929 , veáse en «Acta de la Sesión de la Junta Directiva del 9 de junio de 1929", Fondo del Hogar de los Españoles, loc. cit., exp. 3/1.

38 «Acta de la sesión de la Junta Directiva celebrada el 28 de diciembre de 1930», Fondo del Hogar de los Españoles, loc. cit., exp. 3/1.

39 «Asamblea General celebrada el 12 de marzo de 1933», Fondo del Hogar de los Españoles, loc. cit., exp. $3 / 3$

40 «Carta de los presidentes de las asociaciones al excelentísimo señor embajador», Fondo del Hogar de los Españoles, loc. cit. , exp. 1/13.

41 El liberalismo español limitaba su intervención a las áreas estrictamente benéficas y dejaba la nueva pobreza, derivada de la condición obrera, a la iniciativa de la Iglesia, véase en ESTEBAN DE VEGA, Mariano: «La Asistencia liberal española: beneficencia pública ...», op. cit. , págs.123-138.

Hispania, LXII/2, núm. 211 (2002) 505-520 
yecto global de acción católica, antiliberal y antisocialista ${ }^{42}$. Prueba de ello es la decisión de enviar en noviembre de 1934 un donativo de 100 pesetas para el ejército español «por los últimos sucesos». Aunque esta expresión no nos aclara a qué sucesos se refiere, todo hace pensar que se trata de la represión por la revolución de Asturias de octubre del mismo año. Dicha decisión provocó la recusación de un miembro de la Junta Directiva del Hogar.

Orientaciones políticas conservadoras adoptadas por la Junta Directiva del Hogar se repetirán posteriormente. Así a pesar de su supuesta neutralidad política y de la escasez de recursos para socorrer las necesidades de sus trabajadores asociados, contribuía con 300 francos a una suscripción a favor de la División Azul y de los soldados españoles que luchaban en Rusia a favor de la Alemania nazi ${ }^{43}$. Apenas dos meses antes, el 18 de septiembre de 1941, los soldados alemanes invadían, a petición de la Gestapo, la Pequeña España. Fueron detenidas 350 personas y 13 españoles resultaron encarcelados y deportados a campos de concentración alemanes ${ }^{44}$.

Las orientaciones políticas adoptadas desde la Guerra Civil española por los religiosos claretianos vinculados a la Pleine produjeron una sima entre ellos y los emigrantes españoles, que persistía a mediados de los años cincuenta ${ }^{45}$. El apoyo de los primeros a los sublevados se oponía a un movimiento de solidaridad a favor de los republicanos españoles que se extendió por la Pequeña Espa$\tilde{n} a$. Cincuenta jóvenes de la Pleine se marchaban, antes de la llegada de los brigadistas internacionales, a defender a la Republica española en $1936^{46}$.

Posteriormente, durante la ocupación alemana de París, el compromiso y la participación de los emigrantes económicos españoles de la Pleine en la resistencia, contrastaba con el apoyo económico que desde la Junta Directiva del Hogar de los Españoles, con fuerte influencia eclesiástica y bajo el control del

42 MonTero, Feliciano y Esteban DE VEGA, Mariano: «Aproximación tipológica al mutualismo popular...», op. cit. , págs. 457-471. exp. $3 / 1$.

43 "Junta Directiva del día 9 de noviembre de 1941», Fondo del Hogar de los Españoles, loc. cit.,

${ }_{44}$ Tras el triunfo de los aliados en la II Guerra Mundial, se produjo el regreso a la Pleine de Saint Denis de 6 supervivientes de los 13 españoles y en 1946, con la presencia de La Pasionaria, se daba el nombre de Cristino García, destacado guerrillero en el maquis francés que fue fusilado por el régimen de Franco, a la calle donde se situaba el Patronato Español de Santa Teresa, véase en LILLO, Natacha: «La crisis económica, la guerra civil y la invasión nazi...», op. cit.

45 Las diferencias persistían, como se desprende de la memoria del Real Patronato Español de Santa Teresa de 1955, donde se afirma "no hay que olvidar ciertas circunstancias de tiempos y políticas. La denominación de Cinturón rojo de París aplicada a estos barrios tiene su influencia. El respeto humano, el que dirán los compañeros y vecinos, la ficha de un sindicato más o menos hostil, el mezclar indecuadamente esta o la otra forma de gobierno con la religión...Con todo, y pese a todos estos obstáculos, los que hemos vivido cambios políticos y circunstancias de tan varios colores, observamos un adelanto y mejora indiscutibles, y nuestra acción espriritual está ya casi libre de los prejuicios apuntados», cfr., Real Patronato español Santa Teresa de Jesús en París, 1955, pág. 25.

46 Véase LILLO, Natacha: «La crisis económica, la guerra civil ....», op. cit. 
consiliario, se daba a los intereses nazis en el frente ruso. Sobre todo porque desde el 29 de agosto de 1939, a espaldas de los miembros de la Junta, el consiliario y otros tres miembros decidían depositar los fondos en manos del primero, que imponía el secreto sobre la decisión adoptada para el resto de componentes ausentes de la Junta ${ }^{47}$. Es preciso hacer notar aquí la confluencia de intereses entre la Nueva España franquista y las potencias del Eje por un lado y por otro, el apoyo prestado a las segundas desde la Sociedad de Socorros Mutuos, en la que los religiosos, relegados durante el período republicano, volvían a recobrar la influencia inicial. Sobre todo porque se producía en un contexto de represión alemana sobre los emigrantes económicos españoles de la Pleine Saint Denis, identificados con los aliados, la resistencia francesa y los republicanos españoles.

Más allá de los objetivos reconocidas en los estatutos y de la instrumentalización que el poder político español, a través de la Iglesia, hizo de la organización, la sociedad cumplió, de cara a los emigrantes, otras funciones. En diferentes circunstancias sirvió de instrumento de solidaridad entre los españoles de París, especialmente con ocasión de catástrofes, como la pérdida de su barraca, a causa de un incendio, de un español de Saint-Ouen, la búsqueda de trabajo para los parados o la obtención de rebajas en establecimientos ${ }^{48}$. El asociacionismo amortiguaba también los contrastes culturales que representaba la sociedad francesa para los emigrantes. Por ello, el Hogar de los Españoles organizó actividades culturales y lúdico-recreativas como un festival deportivoreligioso en 1929, una fiesta religioso teatral, un acto de bendición de la bandera, que servía para reforzar los vínculos con España, sobre todo porque tras el desastre de 1898 se instauró la idea de que la emigración era una opción antipatriótica para librarse del servicio militar. También se organizó una excursión a Versalles y se creó una biblioteca de acceso gratuito para los socios. Otra iniciativa que no llegó a cuajar fue la de solicitar al gobierno español la creación en París de una escuela de artes y oficios para que los hijos de los emigrantes se formaran en ella gratuitamente ${ }^{49}$.

El asociacionismo ofrecía oportunidades de sociabilidad y de solidaridad entre los emigrantes. Era un cauce de informaciones sobre trabajo, parientes o

47 «Sesión extraordinaria y secreta de la Junta el día 29 de agosto de 1939», Fondo el Hogar de los españoles, loc. cit. No era la primera vez que el consiliario decidía personalmente sobre los fondos de la asociación. Al menos en otras dos ocasiones, en 1936 y 1937, adoptaba decisiones según su propio criterio, sobre el depósito de los fondos en diferentes entidades bancarias.

48 "Acta de la sesión de la Junta Directiva celebrada el día 12 de julio de 1931», «Acta de la Junta Directiva celebrada el día 8 de enero de 1933", Fondo del Hogar de los Españoles, loc. cit., exp. $1 / 5$ y $3 / 1$.

49 «Reunión de Junta Directiva celebrada el día 13 de diciembre de 1931», «Acta de la sesión de la Junta Directiva celebrada el día 11 de noviembre de 1928», "Acta de la sesión de la Junta Directiva celebrada el 10 de enero de 1929», "Acta de la sesión de la Junta Directiva celebrada el día 14 de julio de 1929», Fondo del Hogar de los Españoles, loc. cit, exps. 1/2 , 1/4, 1/5 y 3/1. 
paisanos que quedaban en España. Es decir era a la vez un vínculo con el país de origen y un instrumento de penetración en la sociedad francesa. Permitía el establecimiento de redes y relaciones en la sociedad de $\operatorname{acogida}^{50}$, pero a la vez difundía entre los emigrantes la cultura de origen y facilitaba el contacto entre los compatriotas, lo que explica la pertenencia a la misma de emigrantes inscritos al mismo tiempo en otras sociedades mutuales. No era de carácter material el único beneficio perseguido al participar en la asociación, razón que explica la pervivencia de esta institución, así como de otras de similar naturaleza, una vez superada la función asistencial para las que fueron creadas ${ }^{51}$.

\section{CONCLUSIONES}

Además del asociacionismo fomentado, como en este caso, por la Iglesia Católica y el Estado, los emigrantes se autoorganizaron en Francia desde el siglo XIX en clubs y asociaciones. Muchos de ellos han pervivido hasta la actualidad, como es el ejemplo que aquí nos ocupa. En el siglo XX cuando la emigración económica a Europa se hizo masiva, El Hogar de los Españoles, junto con otras organizaciones laicas de emigrantes, fueron la base sobre la que se vertebró el movimiento asociativo español en el país vecino. Desde su nacimiento, las organizaciones étnicas se han adaptado a las necesidades de los emigrantes en la sociedad de acogida. Por ello abandonaron, como en este caso, su condición original de sociedades de socorros mutuos, pero mantienen otras funciones, relacionadas con la difusión y recreación de la lengua y cultura española. El cambio se produjo a partir de la firma en 1957 de un convenio de asistencia y seguridad social entre los gobiernos francés y español, que dejaba sin sentido la antigua función asistencial ${ }^{52}$.

so Así por ejemplo, la Cámara de Comercio enviaba en 1928 cuatro invitaciones a la asociación para asistir a la Feria de París

51 Algunos de los primeros socios del Hogar de los Españoles pertenecían ya a otras sociedades como el señor Labín, que formaba parte de la «sociedad de socorros mutuales de obreros de Carbone» o el señor Citores, que tenía problemas por pertenecer simultáneamente a la sociedad de socorros mutuos de la fábrica Gobain, según «Acta de la sesión que la Junta directiva celebró el día 22 de agosto de 1926», Fondo del Hogar de los Españoles, loc. cit., exp. 3/1.

52 Así es porque en la actualidad el Hogar de los Españoles así como otras organizaciones laicas como por ejemplo la Sociedad de Socorros Mutuos y Fraternidad Española de Bèziers, creada el 1 de agosto de 1889, han abandonado toda actividad asistencial, convirtiéndose en asociaciones socioculturales y recreativas sin ánimo de lucro. Han perdido su condición original, de mecanismo para defenderse de los estragos de la enfermedad y de la muerte, para mantenerse en el umbral de la supervivencia cuando los accidentes fortuitos de la vida dan al traste con los ingresos producto del trabajo, según la descripción de las sociedades de socorros mutuos de CUESTA, Josefina: «Las sociedades de Socorros Mutuos en el primer tercio del siglo XX: Sociedad sin Estado, una sociedad fallida», en CASTILlo CASTILlo, Santiago (ed.): Solidaridad desde abajo, op. cit., págs. 409-422. 
Aquí se encuentra una de las principales diferencias entre el asociacionismo español de América y el de Europa. En el viejo continente, tras la Segunda Guerra Mundial, se desarrolló el Estado de Bienestar, del que se beneficiaron también los inmigrantes, lo que hizo desaparecer un sistema asistencial de contribución y gestión directa, representado por las sociedades de socorros mutuos. En América en cambio muchas organizaciones étnicas han mantenimiento su función decimonónica original por las carencias que presentan los estados en este aspecto.

El asociacionismo demuestra que la emigración de los españoles no era una estrategia individual sino que tenía un sentido societal profundo, en la medida en que los emigrantes articulaban recursos organizativos y sociales propios en el país de destino. Lo anterior no significaba que rompiesen con su país de origen sino todo lo contrario, el asociacionismo era un instrumento facilitador de su vida en Francia a la vez que fortalecedor de sus vínculos con España, lo que no resultaba contradictorio sino complementario.

Desde la perspectiva del gobierno español, las asociaciones de emigrantes, cuando eran impulsadas por el propio poder o tenían una fuerte influencia de la Iglesia Católica, constituían una posibilidad de controlar y mediatizar a los emigrantes en el extranjero. A pesar de que se presentaban, como en este caso, como mecanismos apolíticos y sin ideología al servicio de los emigrantes, defendían en realidad intereses políticos y económicos muy concretos del estado español, en una dirección a veces opuesta a la que autónomamente identificaban como propia los emigrantes. La iglesia tutelaba, e incluso, corregía las decisiones de los trabajadores cuando se apartaban de los intereses del estado español, que en este momento se confundían con los de la Iglesia ${ }^{53}$. Los recursos económicos de los trabajadores eran incluso utilizados a favor del poder político.

53 Véase la información de la maestra nacional en relación con la actividad docente desarrollada por el Real Patronato Español de Santa Teresa, quien afirma, en relación con la situación moral de los alumnos de la Pleine Saint Denis, que los de mejor espíritu son los nacidos en España, mientras que el laicismo reinante en la sociedad francesa y las propagandas envenenadoras son una influencia perjudicial, "pero a pesar del medio ambiente ...la labor que (...) se realiza a través de la escuela de este Patronato Español de Saint Denis es una labor completa, no solamente cultural, sino religiosa y patriótica», cfr. Real Patronato Español Santa Teresa..., loc. cit., pág. 34 